\title{
La tutela cautelar en los procesos contra la administración pública en Ecuador
}

\author{
Benjamín Marcheco Acuña*1
}

\begin{abstract}
RESUMEN
En el presente trabajo se aborda la problemática de la tutela cautelar contra la Administración pública en derecho ecuatoriano, que abarca dos regimenes completamente dispares, tanto por su amplitud como por su intensidad: el de la jurisdicción constitucional, regulado en la Ley de Garantias Jurisdiccionales y de Control Constitucional de 2009, y el de la jurisdicción contencioso-administrativa y tributaria, recogida en el nuevo Código Orgánico General de Procesos; realizando un análisis crítico de dicha institución a la luz de sus fundamentos teóricos, tanto doctrinales como jurisprudenciales, a los efectos de poner de manifiesto las imperfecciones de que adolece el actual sistema y realizar propuestas en función de su perfeccionamiento.
\end{abstract}

Medidas cautelares - tutela judicial efectiva - justicia administrativa

\section{The interim protection in processes against the public administration in Ecuador}

\begin{abstract}
This paper makes an analysis of the precautionary measures regime aganist the public administration in Ecuador legal system, both before constitutional jurisdiction, as in administrative and tax process of the General Organic Code of Process, through the theoretical basis of this institute, in order to highlight the limitations established in the Ecuadorian system, and suggest the necessary changes towards the improvement of $i$.
\end{abstract}

Precautionary measures - effective judicial protection - administrative justice

* Licenciado en Derecho, Universidad de Oriente, Cuba. Master en Derecho Constitucional, Universidad Internacional Menéndez Pelayo - Centro de Estudios Políticos y Constitucionales. Master en Especialización en Investigación en Derecho, Universidad de Zaragoza. Master en Derecho Constitucional y Administrativo, Universidad de La Habana. Doctor en Ciencias Jurídicas, Universidad de La Habana. Profesor de Derecho, Universidad de Guayaquil, Ecuador. Correo electrónico: benjamarcheco@gmail.com

Artículo recibido el 27 de enero de 2016 y aceptado para su publicación el 1 de marzo de 2017. 


\section{INTRODUCCIÓN}

$\mathrm{L}$ a duración "normal" de cualquier proceso puede suponer, para quien acude a él en busca de la protección de sus derechos, el peligro de la frustración de sus pretensiones, debido a la no poco frecuente demora en las resoluciones definitivas, derivada de los extendidos plazos procesales, de las frecuentes interrupciones, de la conducta de las partes, a lo que habría que agregar el colapso de los tribunales por el aumento de los litigios o la falta de los recursos humanos necesarios. Para mitigar los efectos negativos que respecto de la eficacia de la justicia genera esta situación, los mecanismos de tutela cautelar se han alzado como instrumentos idóneos para el aseguramiento del cumplimiento efectivo del resultado del proceso, evitando que la sentencia se convierta, para el vencedor de la controversia, en un instrumento sin ninguna utilidad práctica.

El instituto de la tutela cautelar, sustentado en el principio formulado por el derecho italiano a principios del siglo XX según el cual "el proceso para obtener razón no puede convertirse en un daño para quien tiene la razón”, responde a la necesidad "efectiva y actual" de alejar el temor de un daño jurídico ${ }^{1}$. En palabras de Calamandrei, la tutela cautelar "...trata, como las resoluciones que el derecho inglés engloba bajo la denominación de Contempt of Court, de salvaguardar el imperium iudicis, es decir, trata de impedir que la soberanía del Estado, en su más alta expresión que es la Justicia, se reduzca a ser una tardía e inútil expresión verbal, una vana ostentación de lentos mecanismos destinados, como la guardia de la ópera buffa, a llegar siempre demasiado tarde" 2 .

Ello así, las providencias cautelares representan una conciliación entre dos exigencias de la justicia frecuentemente opuestas, la celeridad y la ponderación: entre hacer las cosas pronto pero mal, y hacerlas bien, pero tarde, las providencias cautelares procuran, ante todo, hacerlas pronto, dejando que el problema del bien y el mal, esto es, el de la justicia intrínseca de la decisión, se resuelvan más tarde, con la necesaria ponderación, "en las reposadas formas del proceso ordinario"3.

De esta forma, el fundamento de la tutela cautelar radica en el derecho constitucional a la tutela judicial efectiva (art. 75 ConsE) ${ }^{4}$. Como apunta Schmidt-Assmann, es la protección cautelar, la que junto con la intensidad del control judicial, la que caracteriza una tutela efectiva de los derechos ${ }^{5}$, ello en el entendido de que este solo puede

${ }^{1}$ Chiovenda, G. Instituciones de Derecho Procesal Civil, trad. de la segunda edición italiana y notas de derecho español de E. Gómez Orbaneja, Revista de Derecho Privado, Madrid, 1936, p. 299

${ }^{2}$ Calamandrei, p. Introducción al estudio sistemático de las providencias cautelares, trad. de S. Santis, Editorial Bibliográfica Argentina, Buenos Aires, 1945, p. 140

${ }^{3}$ Calamandrei, p. Introducción..., ob. cit., p. 140

${ }^{4}$ Art. 75. Toda persona tiene derecho al acceso gratuito a la justicia y a la tutela efectiva, imparcial y expedita de sus derechos e intereses, con sujeción a los principios de inmediación y celeridad; en ningún caso quedará en indefensión. El incumplimiento de las resoluciones judiciales será sancionado por la ley.

${ }^{5}$ Schmidt-Assmann, E. La Teoría General del Derecho Administrativo como Sistema, Instituto Nacional de Administración Pública- Marcial Pons, Madrid-Barcelona, 2003, p. 237 
materializarse por medio de las previsiones que garanticen la observancia plena de las resoluciones derivadas del proceso o que estas le reporten alguna utilidad al vencedor ${ }^{6}$.

La tutela cautelar en el contencioso administrativo, sin embargo, además de todas las dificultades propias de cualquier proceso, se enfrenta a los problemas adicionales que derivan de la actividad de enjuiciar a la Administración y que tienen que ver con los tradicionales privilegios que su condición de poder público le permiten y que condicionan la ordenación del proceso.

Frente a este panorama, ante la existencia de un poder público con la capacidad de actuar aun cuando haya sido puesta en cuestionamiento la legalidad de su decisión, la protección cautelar se presenta como una garantía esencial de la tutela judicial efectiva del ciudadano.

Dentro del contexto ecuatoriano, la situación de la protección cautelar frente a las actuaciones del poder público es bastante dispar, en los dos sistemas que actualmente existen: el regulado en la Ley de Garantías Jurisdiccionales y de Control Constitucional (LGJCC, No 0/2009) para la protección de los derechos constitucionales y el de la justicia administrativa ordinaria, en la aún vigente Ley de la Jurisdicción Contencioso Administrativa (LJCA; $N^{\circ}$ 35/1967). El primero, destinado más a la tutela provisional de la situación jurídica subjetiva de quien reclama un derecho con apariencia de razón que al aseguramiento de la eficacia de la sentencia ${ }^{7}$, está presidido por criterios mucho más amplios para el otorgamiento de las medidas precautorias; mientras el segundo, en consonancia con el modelo que le sirviera de inspiración, el francés del excés de pouvoir, se fundamenta en la exacerbación del privilegio de autotutela ejecutiva de la Administración pública, haciendo descansar su régimen cautelar únicamente en la técnica de suspensión del acto administrativo con carácter restrictivo ${ }^{8}$. El nuevo Código Orgánico General de Procesos (COGEP), aprobado por la Asamblea Nacional el 12 de mayo de 2015, a pesar de consolidar muchas de las transformaciones que se han producido en las últimas décadas respecto de los fundamentos de la justicia administrativa, encaminada a un control universal y plenario de la Administración pública, tanto en las legislaciones comparadas como en el propio ordenamiento ecuatoriano a partir, sobre todo, de la promulgación de la Constitución de 2008 (ConsE), en lo que respecta a la protección cautelar tanto en el proceso contencioso-administrativo como en el tributario no introdujo cambios

\footnotetext{
${ }^{6}$ Respecto del concepto y contenido de la tutela judicial efectiva en el derecho ecuatoriano. cfr: Aguirre Guzmán, V. "El derecho a la tutela judicial efectiva: una aproximación a su aplicación por los tribunales ecuatorianos", Foro, Revista de Derecho, UASB, No. 14, 2010, pp. 23- 43.

${ }^{7}$ Según la Exposición de motivos y el art. 6 de la Ley: "las medidas cautelares tienen como finalidad prevenir, impedir o interrumpir la violación de un derecho”.

${ }^{8}$ La suspensión de la ejecución podrá concederse únicamente contra actos administrativos que hayan causado estado y que implique una obligación económica a favor del Estado, siempre que se afiance el interés económico de las entidades públicas o semipúblicas mediante el depósito bancario de la cantidad demandada y los intereses devengados hasta la fecha del depósito, más un diez por ciento de dicha cantidad, por intereses a devengarse y costas o asegurando la obligación con hipoteca, prenda o fianza bancaria, o en otra forma a satisfacción del Tribunal (art. 75). "Salvo lo dispuesto en el artículo precedente, en ningún caso se suspenderá la ejecución o cumplimiento del acto administrativo” (art. 76).
} 
significativos en relación con su antecesora la LJCA; situación que, sin dudas, deriva en una limitada eficacia de la tutela judicial efectiva en estas materias, contradiciendo con ellos los propios fundamentos del constitucionalismo ecuatoriano respecto de la protección de los derechos de los ciudadanos frente al poder.

En este sentido, este trabajo se propone realizar un análisis crítico del marco regulatorio del régimen cautelar en los dos sistemas de justicia administrativa, tanto el de clave constitucional de la LGJCC $^{9}$ como el de los procesos contencioso-administrativo y tributario del COGEP; a la luz de los elementos teóricos doctrinales y de derecho comparado que fundamentan dicha institución y de los propios fundamentos constitucionales de la tutela judicial efectiva, a los fines de realizar propuestas de solución que puedan ser tenidas en cuenta en función de corregir las imperfecciones de que adolece el actual sistema, que permitan garantizar, de cara a los ciudadanos, una justicia administrativa y tributaria eficaz en tutela de sus derechos e intereses.

El desarrollo del trabajo se ha estructurado en cinco epígrafes: el primero dedicado a exponer las transformaciones de la institución cautelar en los últimos años en los sistemas procesales administrativos de Europa y Latinoamérica, en el segundo se analizan los caracteres y los presupuestos teóricos de las medidas cautelares, el tercero y el cuarto se dedican, respectivamente, a la valoración del régimen cautelar frente a las actuaciones de la Administración pública en el ordenamiento procesal ecuatoriano, tanto en la LGJCC como en el COGEP; y un último epígrafe conclusivo con las propuestas de líneas básicas para la reforma de la tutela cautelar en el contencioso administrativo y tributario.

\section{LAS TRANSFORMACIONES DE LA TUTELA CAUTELAR ANTE LA JUSTICIA ADMINISTRATIVA EN EL DERECHO COMPARADO}

El desarrollo de las medidas cautelares (también denominadas "precautorias", "preventivas", "provisionales" o simplemente "cautelas" ) en el derecho procesal administrativo es de data muy reciente, de apenas fines del siglo XX y es el resultado de una larga evolución doctrinal y jurisprudencial que, con fundamento en el derecho a la tutela judicial efectiva, ha superado la visión tradicional del contencioso que limitaba la tutela cautelar a una única medida posible: la suspensión de la ejecución de los actos administrativos.

El redimensionamiento de la tutela cautelar está conectado necesariamente con la evolución del objeto del contencioso-administrativo y la superación del restrictivo criterio del proceso revisor del acto. Al ser la pretensión principal el eje central del proceso,

9 Hablamos de "justicia administrativa en clave constitucional" toda vez que la LGJCC regula el procedimiento de solución de conflictos entre particulares y autoridades públicas no judiciales o particulares en ejercicio de funciones públicas (justicia administrativa), con motivo de la vulneración de derechos constitucionales. 
los jueces deben tender a asegurar el cumplimiento efectivo de la sentencia, para que el resultado del proceso no se transforme en algo inútil o inoportuno ${ }^{10}$.

Los debates doctrinales ${ }^{11}$ y las soluciones jurisprudenciales en torno al contenido del derecho a la tutela judicial han puesto el acento en los últimos años en la construcción de una sólida base teórica respecto de las medidas cautelares ante la justicia administrativa, presentándolas como la institución necesaria e idónea para limitación de la autotutela ejecutiva de la Administración, con lo que se ha logrado revertir el carácter extraordinario o excepcional de estas convirtiéndolas en un instrumento de tutela jurisdiccional ordinaria. De esta manera, el aseguramiento del derecho a la tutela judicial efectiva se ha supeditado cada vez más a los sistemas cautelares que ofrezcan mayores garantías de eficacia de la resolución final, para lo que deben partir de asegurar la mayor flexibilidad posible en la concesión de este tipo de providencias:

“...flexibilidad -dice Chinchilla- en el cuándo, en el cómo y en el porqué de la adopción de las medidas cautelares. Flexibilidad en el sentido de que deben adoptarse todas las medidas cautelares posibles y no solo la suspensión; flexibilidad en el sentido de que puedan adoptarse tanto antes como después de la interposición del recurso administrativo o judicial; y flexibilidad, por último, en cuanto a los criterios que en cada caso concreto pueden y deben emplear los órganos judiciales para otorgar o denegar la tutela cautelar solicitada" 12 .

En definitiva, como asegura Gordillo, es en un adecuado régimen cautelar donde está en juego la visión que se tenga de la justicia. "En el mundo hay por doquier una dilación escandalosa de los procesos y es inevitable admitir con García de Enterría y Estoup que el honor de la justicia, nada menos, está precisamente en estos

${ }^{10}$ Cassagne, J. C. y González Pérez, J. La Justicia Administrativa en Iberoamérica, LexisNexis- Abeledo Perrot, Buenos Aires, 2005, p. 97

11 A modo de ejemplo y sin ánimos de exhaustividad, por lo extenso de la bibliografía sobre el tema puede citarse: Parejo, L. "La tutela judicial cautelar en el orden contencioso administrativo", Revista Española de Derecho Administrativo, No 49, 1986, pp. 19- 44; López Ramón, F. "Límites constitucionales de autotutela administrativa”, Revista de Administración Pública, No 115, 1988, pp. 57-98; Chinchilla, C. (1), La tutela cautelar en la nueva justicia administrativa, Civitas, Madrid, 1991 (2), "El derecho a la tutela cautelar como garantía de la efectividad de las resoluciones judiciales”, Revista de Administración Pública, No 131, 1993, pp. 167-189 (3), “Tutela cautelar”, en Leguina, J. y Sánchez Morón, M. (dirs.) Comentarios a la Ley de la Jurisdicción contencioso-Administrativa, LexNova, Valladolid, 1999, pp. 563- 606; García de Enterría, E. La batalla por las medidas cautelares, Civitas, Madrid, 1995; Fenor de la Maza, Á. Nuevas Perspectivas en el Proceso Contencioso-Administrativo, Montecorvo, Madrid, 1997; De la Serna, M. "Las medidas cautelares”, Documentación Administrativa, $\mathrm{N}^{\circ}$ 254-255, 1999, pp. 179- 196; Hernández Corchete, J. A. "Medidas cautelares en lo contencioso administrativo y Constitución. Una propuesta para un debate aún abierto", Cuadernos de Derecho Público, N 10, 2000, pp. 73- 88; Fuertes, M. “Tutela cautelar...”, ob. cit., pp. 57- 87; los 15 artículos recogidos en la obra colectiva monográfica: Damsky, I. et al. (coords.): Las Medidas Cautelares en el Proceso Administrativo en Iberoamérica, Asociación de Magistrados de Tribunales de lo Contencioso Administrativo de los Estados Unidos Mexicanos, México, 2009; Allena, M. y Fracchia, F. "Il ruolo e il significato della tutela cautelare", Diritto Processuale Amministrativo, No 1, 2011, pp. 191- 239.

${ }^{12}$ Chinchilla, C. La tutela cautelar en la nueva justicia administrativa, ob. cit., p. 177. 
juicios cautelares y rápidos pues las medidas cautelares son la tabla de salvación de la -desesperadamente lenta- justicia administrativa" ${ }^{13}$.

En este sentido, las últimas reformas en los sistemas procesales administrativos de varios países de Europa y Latinoamérica apuntan de forma creciente hacia la apertura del régimen cautelar, a partir de criterios de flexibilidad y de amplia disponibilidad para la jurisdicción, eliminando incluso las diferencias con el proceso y hasta aplicándose con carácter supletorio la regulación de este ${ }^{14}$.

Con Alemania se inicia el camino revolucionario de los sistemas cautelares, al establecer por primera vez, con la reforma de la VwGO de 1991, un régimen dual y abierto de protección cautelar mediante el reconocimiento, por un lado, del carácter suspensivo de la acción impugnatoria respecto de la ejecución del acto ${ }^{15}$, salvo los casos excepcionales que se prevén en la propia ley (art. 80.1) y la atribución a los jueces de amplios poderes para acordar, en los casos de reclamaciones de naturaleza prestacional, órdenes provisionales incluso con anterioridad a la interposición de la demanda, cuando exista peligro de que por una modificación de las circunstancias se pueda frustrar o dificultar esencialmente la realización de un derecho del solicitante o para la regulación de un estado provisional referido a una relación jurídica litigiosa, cuando dicha regulación aparezca como necesaria, sobre todo en relaciones jurídicas de cierta permanencia, para impedir perjuicios esenciales o la amenaza de violencia o por otras razones $\left(\right.$ art. 123) ${ }^{16}$.

El derecho francés, en el 2000, introduce dos tipos de recursos cautelares (référés) ${ }^{17}$ : uno destinado a permitir la suspensión de la ejecución del acto administrativo recurrido cuando lo justifique la "urgencia" del caso y la razón invocada de nulidad suscite una "duda seria" respecto de la legalidad de la decisión ${ }^{18}$ y el otro (que se asemeja al recurso

${ }^{13}$ Gordillo, A. Tratado de Derecho Administrativo y obras selectas, Buenos Aires, Fundación de Derecho Administrativo, 2013, t- 2, pp. XIII-30-31.

${ }^{14}$ González Pérez, Jesús. "La Justicia Administrativa”, en Cisneros Farias, G. et al. (coords.), Justicia Administrativa, Segundo Congreso Iberoamericano de Derecho Administrativo, UNAM, México, 2007, p. 261.

${ }^{15}$ El sistema también ha sido blanco de las críticas. Para Schmidt-Assmann, la insuficiencia del esquema en que se funda este modelo se manifiesta sobre todo en los supuestos de relaciones multilaterales donde puede existir un tercero afectado no recurrente, ya que aquí pueden existir derechos subjetivos merecedores de protección en los dos lados de la relación jurídica. "Resulta difícil de justificar por qué -dice-, ante una situación abierta derivada de la pendencia de un proceso aún no finalizado en firme, uno de los particulares afectados (el recurrente) se beneficia de un instrumento procesal (el efecto suspensivo) en perjuicio sistemático del interés jurídico opuesto de su competidor (el destinatario/beneficiario del acto impugnado)". SchmidtAssmann, E. La Teoría General ..., ob. cit., p. 238.

16 También se incluyen dentro de las regulaciones de la VwGO acerca de las medidas cautelares el art. 47.8 , referente a la emanación de órdenes provisionales en el procedimiento de control de normas de los Länder con rango inferior al de la ley.

${ }^{17}$ Introducidos por la ley de 30 de junio de 2000, integrada en los artículos L. 521-1 a L. 523-1 del Código de Justicia Administrativa.

${ }^{18}$ El requisito de "urgencia" ha sido definido por la jurisprudencia del Consejo en términos coincidentes con el del perjuicio irreparable: Así, habría urgencia cuando la ejecución de la decisión administrativa es susceptible de causar un "perjuicio suficientemente grave e inmediato" al demandante, o a otra persona privada, o a la misma Administración. CE, 19 de enero de 2001, Confederación Nacional de Radios Libres, 
de amparo de otros ordenamientos) dirigido a salvaguardar las libertades fundamentales garantizadas por la Constitución, cuando hayan sido atacadas por la Administración "de manera grave y manifiestamente ilegal”.

La legislación italiana, en 2010, también introdujo importantes novedades al sistema cautelar. El decreto legislativo $\mathrm{N}^{0} 53$ dispuso una suerte de efecto suspensivo del recurso ante el juez administrativo en el caso de contratos públicos, y posteriormente el Códice procesal (d. lgs. $\mathrm{N}^{\circ} 104$ de ese mismo año) puso de manifiesto la centralidad que ocupa el régimen cautelar dentro del proceso administrativo ${ }^{19}$; estableciendo un régimen abierto con medidas que abarcan, incluso, la decisión del fondo de manera anticipada y simplificada (art. 55.10).

En Portugal, el Código del Proceso de los Tribunales Administrativos estatuye un sistema autónomo de tutela de urgencia, que recoge tanto la tutela cautelar provisional ${ }^{20}$ como la técnica de anticipación ${ }^{21}$ en "procesos simplificados y estructuralmente adecuados para las situaciones de urgencia" 22 . El derecho español, como los latinoamericanos de Costa Rica, Venezuela, Colombia, Perú, México y la provincia argentina de Buenos Aires, prevén también un numerus apertus de medidas precautorias que pueden acordar los tribunales ${ }^{23}$.

Rec. CE p. 29; CE, 28 de febrero de 2001, Prefecto de Alpes Marítimos, Rec. p. 109. La "duda seria” no es otra cosa que el fumus boni iuris, que deriva de algún argumento invocado por el demandante en su recurso que deja pensar al juez en que el acto impugnado es probablemente es ilegal. CE, 28 de febrero de 2001, Philippart y Lesage, Rec. CE p. 111.

19 Allena, M. y Fracchia, F. "Il ruolo...", ob. cit., p. 196.

${ }^{20}$ El título V (arts. 112 al 134) del Código regula en forma amplia y detallada el proceso cautelar. El art. 112 recoge un numerus clausus de medidas provisionales que puede adoptar el juez, además de las propias del proceso civil, que podrá acordar con las debidas adaptaciones en los casos en que se consideren necesarias.

${ }^{21}$ La técnica de anticipación (arts. 121 y 132. 7) consiste en adelantar el pronunciamiento de la causa principal, decidiendo así sobre el fondo del asunto cuando, atendiendo a la naturaleza de las cuestiones debatidas y a la gravedad de los intereses implicados, la urgencia manifiesta en la resolución definitiva del proceso permita concluir que la situación no se compadece con la adopción de una simple medida cautelar y consten en el proceso todos los elementos necesarios al efecto.

${ }^{22}$ Fonseca, I. "Os Processos cautelares na justica administrativa. Uma parte da categoria da tutela jurisdicional de urgencia”, en Pereira da Silva, V. (coord.), Temas e problemas de processo administrativo, Lisboa, Instituto de Ciências Jurídico-Políticas segunda edición revisada y actualizada, 2011, p. 208.

${ }^{23}$ Cfr. El art. 129.1 de la Ley Reguladora de la Jurisdicción Contencioso Administrativa de España (1998); el Título II del Libro II, arts. 55 al 62 y 120 al 124del, Código del Proceso Administrativo italiano (2010); el art. 22. 2 del Código del Proceso Contencioso Administrativo de la provincia argentina de Buenos Aires (1999), el art. 24 de la Ley Federal del Procedimiento Contencioso Administrativo de México, el art. 19.1 del Código Procesal de lo Contencioso-Administrativo de Costa Rica (2006); los arts. 35 y 37 de la Ley que Regula el Proceso de lo Contencioso-Administrativo en Perú (2002) y el art. 4 de la venezolana Ley Orgánica de la Jurisdicción Contencioso-Administrativa (2009); arts. 229 al 241 del Código del Procedimiento Administrativo y de lo ContenciosoAdministrativo de Colombia (2011). En este último se prevé la posibilidad de adoptar medidas cautelares aun de oficio, en los casos en los procesos que tengan por finalidad la defensa y protección de los derechos e intereses colectivos y en los procesos de tutela que sean del conocimiento de la jurisdicción contencioso administrativa (art. 229, parágrafo). 
La excepción es Nicaragua ${ }^{24}$, cuyo régimen se reduce a la regulación de la técnica de suspensión del acto.

De las distintas construcciones jurisprudenciales y las propias regulaciones legales pueden citarse, sin ánimo de exhaustividad, algunas de las medidas que se han ido desarrollando en el proceso administrativo, como son:

a) suspensión de la ejecutividad del acto o reglamento impugnado. Es la tradicional y más común de todas las medidas cautelares, a la que se añade el carácter suspensivo de la demanda, de la ejecución del acto recogido en algunos ordenamientos;

b) suspensión de los efectos del acto administrativo recurrido hasta que la administración resuelva el recurso administrativo que agota dicha vía ${ }^{25}$;

c) el restablecimiento total o parcial de la situación jurídica existente al momento de ser esta modificada o extinguida por la actuación administrativa;

d) prohibición de innovación, mientras dura el proceso, de la situación de hecho o de derecho existente al momento de disponerse la medida. Es, concretamente, una orden específica de no realizar actos que alteren o modifiquen el estado del objeto litigioso;

e) aseguramiento de bienes objeto del litigio;

f) regulación provisional de derechos o facultades, tendente a una continuidad de su ejercicio durante la litispendencia (ej. la autorización provisional al interesado para iniciar o proseguir una actividad o adoptar una conducta);

g) la ejecución provisional de sentencias que aún no han adquirido firmeza;

h) la admisión provisional en pruebas y concursos;

i) la atribución provisional del poder de disposición sobre un bien;

j) la regulación provisional de una situación jurídica, en particular imponiendo a la Administración obligaciones (positivas o negativas) pertinentes a los fines de protección (p. ej. la obligación de pago de una cantidad por cuenta de prestaciones debidas o a título de reparación provisional o a la verificación y constancia de las circunstancias de un objeto o situación litigiosas) ${ }^{26}$;

k) la intimación a la adopción o abstención de una conducta por parte de la Administración o de un particular, en especial si este último es un concesionario,

${ }^{24}$ Arts. 62 al 68 de la LRJCA. Un estudio amplio acerca del régimen cautelar de Nicaragua puede verse en: Navarro, K. y Sendín, M. "Medidas cautelares y proceso contencioso-administrativo en Nicaragua", en Damsky, I. et al.. Las Medidas Cautelares..., ob. cit., pp. 383- 408.

${ }^{25}$ Es una medida del derecho argentino, mediante la que el administrado obtiene tutela aparentemente sin forzar el sistema de agotamiento de la vía administrativa previa y sin un perjuicio mayor para la administración, quien, con su propia diligencia determina la duración de la medida cautelar dictada en su contra resolviendo el recurso. Carrillo, Santiago. "Medidas cautelares contra el Estado en Argentina", en Damsky, I.et al., Las Medidas Cautelares..., ob. cit., p. 118.

${ }^{26}$ Esta última resulta de utilidad en los casos de inexistencia o deficiente documentación de la situación o el objeto litigioso en el expediente administrativo, pues ello condiciona el alcance de la pretensión y aun la propia identificación de su objeto y contenido. 
en el supuesto de que se alegue la vulneración o posibilidad fundada de vulneración de normas de Derecho administrativo;

1) las que operan en circunstancias determinantes de una urgencia inaplazable, ante la posibilidad de una actuación de la Administración que pueda inutilizar el buen fin del proceso cautelar;

m) medidas cautelares autosatisfactivas. Se trata de medidas excepcionales que se adoptan en supuestos en los que se encuentran en peligro derechos esenciales de la persona e implican la concesión definitiva de la pretensión de fondo, que puede ser otorgada solo ante la manifiesta insuficiencia de las demás medidas cautelares previstas en el ordenamiento procesal ${ }^{27}$.

\section{CARACTERES Y PRESUPUESTOS TEÓRICOS DE LAS MEDIDAS CAUTELARES}

Siguiendo la definición de Calamandrei ${ }^{28}$, la providencia cautelar es una medida de "anticipación provisoria de ciertos efectos de la providencia definitiva, encaminada a prevenir el daño que podría derivar del retardo de la misma”. De este modo se le entiende como un acto procesal del órgano jurisdiccional que constituye una decisión de fondo, valorativa de las circunstancias de hecho y de derecho aparentes al momento de su adopción, requerida como reacción inmediata y provisional, tendente a superar el peligro de la pérdida o menoscabo de pruebas, bienes o derechos, que pudiera resultar de la eventual o concreta desigualdad de las partes en orden a la disposición de aquellas desde el origen de la controversia judicial y hasta el momento de su composición efectiva.

Los caracteres que identifican a las medidas cautelares son diversos. Entre las más relevantes que señala la doctrina procesalista ${ }^{29}$ se encuentran:

a) provisionalidad o provisoriedad: en tanto están destinadas a regir mientras no sobrevenga una situación o cambio de circunstancias que demuestren la pertinencia de su cese o modificación;

b) tramitación sumaria: el conocimiento judicial previo a su dictado es limitado y fragmentario, con el fin de asegurar su eficacia pueden ser cumplidas inaudita alteram pars;

${ }^{27}$ Carrillo, S. "Medidas cautelares...", ob. cit., p. 119

${ }^{28}$ Calamandrei, p. Introducción..., ob. cit, p. 45

29 Podetti, J.R. Tratado de las Medidas Cautelares, segunda edición actualizada por el Dr. Víctor A. Guerrero Leconte, Ediar S.A, Buenos Aires, 1969; pp. 33- 37; Calamandrei, p. Introducción..., ob. cit, passim; Cortés Domínguez, V. et al.. Derecho Procesal Civil. Parte General Madrid, Colex, 2001, pp. 578579; Ottolenghi, M. "Medidas precautorias", Estudios de Derecho Procesal en Honor de Hugo Alsina, Ediar S. A. Editores, Buenos Aires, 1946, p. 517; Gallegos Fedriani, p. Las medidas cautelares contra la Administración pública, segunda edición, Ábaco, Buenos Aires, 2002, pp. 39-40. 
c) instrumentalidad: ya que no constituyen un fin en sí mismas, sino que su función es la de asegurar del resultado de la causa principal. Esta instrumentalidad no significa pendencia del proceso principal sino que basta con que tribute a él. Por tanto, puede ser autónomo respecto de aquel, pues una cosa sería la pretensión declarativa o de condena y otra la cautelar, que respondería a fundamentos distintos.

d) fungibilidad: en el sentido de que algunas pueden ser sustituidas unas por otras, según se quiera mayor o menor intensidad de la tutela;

e) funcionalidad: pues deben adaptarse a la naturaleza de la acción que se pretende ejercitar.

Para la concesión de la medida cautelar resulta imprescindible la constatación de ciertos presupuestos que, además de los generales a todo proceso, operan especialmente para esta institución: el periculum in mora, el fumus boni iuris, la vigencia del interés general y la prestación de caución.

\subsection{El periculum in mora}

Como se ha señalado, la razón de ser de la tutela es la prevención del riesgo de frustración de la sentencia que el empleo del tiempo necesario de los procesos acarrea. El habitual retraso en la decisión de la causa, puede en ocasiones conllevar a que se causen graves daños al reclamante a consecuencia de la inadecuada conducta procesal de su contraparte. De esta manera, el periculum in mora opera como un requisito habilitante para la concesión de providencias cautelares. Para algunos, constituye la esencia misma de la medida cautelar, su criterio rector, pues "el objeto mismo de la medida cautelar consiste en asegurar las resultas del proceso evitando que la sentencia que se dicte no pueda llevarse a puro y debido efecto" 30 .

Empero, para la funcionalidad del periculum in mora en la concesión de la providencia cautelar no basta la alegación del peligro del daño y que la medida solicitada tenga por ello la finalidad de prevenirlo, sino que es preciso, además, que se trate de un peligro inminente que haga de la medida cautelar un remedio urgente, en cuanto sea de prever que la demora transforme el daño temido en un daño efectivo y, en este sentido, la lentitud de la tutela ordinaria no pueda impedir el resultado dañoso. De ahí que el periculum in mora no tendría razón de ser en tanto fuese posible anticipar la resolución definitiva ${ }^{31}$. A estas dos condiciones (urgencia y necesidad) del periculum in mora habría

${ }^{30}$ Parejo, L. Derecho Administrativo, Ariel, Barcelona, 2003, p. 1197.

31 “También la tutela ordinaria - dice Calamandrei- puede tener un objeto preventivo; también la providencia definitiva (no cautelar), puede, en ciertos casos, dictarse con carácter de urgencia, consiguiendo de este modo que la tutela ordinaria llegue sin retardo. Pero para que surja el interés específico en reclamar una medida cautelar, es necesario que a estos dos elementos (prevención y urgencia) se añada un tercero, que es en el que propiamente reside el alcance característico del periculum in mora; esto es, hay necesidad de que para obviar oportunamente el peligro de daño que amenaza el derecho, la tutela ordinaria se manifieste como demasiado lenta, de manera que, en espera de que se madure a través del largo proceso ordinario, la 
que añadir la condición de irreparabilidad (o de muy difícil reparación) del daño que pretende prevenirse, pues, en caso contrario, prevalecería el principio de ejecutividad de la resolución administrativa si, en definitiva, el perjuicio pudiera remediarse una vez dictada la sentencia.

\subsection{El fumus boni iuris}

El otro criterio tradicional en que se sustenta la concesión de las medidas cautelares, siendo para algunos su "presupuesto esencial y suficiente" 32 , es el de apariencia de buen derecho fumus boni iuris, que opera ante la apariencia más o menos manifiesta de la ilegalidad o contradicción con los principios generales del Derecho de la decisión administrativa combatida ${ }^{33}$. Para su operatividad no se requiere, por tanto, una prueba acabada de la verosimilitud del derecho debatido en el proceso principal, extremo que solo puede alcanzarse al tiempo de la sentencia, ni es menester un examen exhaustivo de las relaciones que vinculan a las partes, bastando que mediante un estudio prudente -apropiado al estado del trámite- sea dado percibir un fumus bonis iuris en el peticionario ${ }^{34}$. Es suficiente entonces con que exista la probabilidad o la posibilidad fundada de que el derecho exista o que tenga apariencia de verdadero. En definitiva -apunta Gordillo-, el fundamento de la medida cautelar no depende de un conocimiento exhaustivo y profundo de la materia controvertida en el proceso principal, sino de un conocimiento periférico o superficial encaminado a obtener un pronunciamiento de mera probabilidad acerca de la existencia del derecho discutido, de allí que resulte suficiente la comprobación de la apariencia o verosimilitud del derecho invocado por el actor ${ }^{35}$.

El presupuesto del fumus boni iuris parte, como el periculum in mora, de la existencia de un riesgo de perjuicios para el que solicita la tutela cautelar, pero a diferencia de aquel, no lo hace desde la perspectiva formal de la simple reparabilidad de dichos perjuicios, sino desde la perspectiva de la incidencia de los mismos precisamente sobre la tutela efectiva que en el proceso ha de darse a quien ostente los derechos o intereses legítimos protegibles. Más llanamente -dice García de Enterría-, el perjuicio atendible por quien dispone la medida cautelar debe consistir en el riesgo de que se frustre la tutela efectiva que corresponde otorgar a la sentencia final. Es ese riesgo el que obliga al juez a intentar una valoración prima facie de las respectivas posiciones, de forma que debe otorgar la tutela cautelar a quien tenga "apariencia de buen derecho", precisamente para que la parte que sostiene una posición injusta manifiestamente no se beneficie con la larga duración del proceso y con la frustración, total o parcial, que de ella va a

providencia definitiva, se deba proveer con carácter de urgencia a impedir con medidas provisorias que el daño temido se produzca o se agrave durante aquella espera” . Calamandrei, p. Introducción..., ob. cit., pp. 41-42.

32 Chinchilla, Carmen "El derecho a la tutela cautelar...", ob. cit., p. 172.

33 García de Enterría, E. "La aplicación de la 'apariencia de buen derecho' como base de las medidas cautelares en el recurso directo contra reglamentos”, Revista de Administración Pública, No 125, 1991, p. 417.

${ }^{34}$ Gordillo, A. Tratado..., ob. cit., p. XIII-32.

${ }^{35}$ Gordillo, A. Tratado..., ob. cit., p. XIII-31. 
resultar para la otra parte $\mathrm{e}^{36}$. Para Coca, la valoración del principio de la apariencia de buen derecho debe armonizarse con la existencia del perjuicio, pero con mantenimiento del privilegio de la autotutela ejecutiva de la Administración cuando el balance de los dos parámetros sea neutro y se pueda por tanto esperar por la decisión definitiva. No tiene sentido -sostiene- suspender cautelarmente una ejecución que no vaya a causar daños de difícil restitución, y tampoco tiene justificación hacerlo cuando no se intuye un resultado favorable al administrado ${ }^{37}$.

\subsection{La observancia del interés general}

El interés general, en la consideración del Consejo de Estado francés, constituye la "clave de bóveda" del derecho administrativo, la finalidad última de la acción pública, que se encuentra en la base de todo el quehacer del Estado y al que el juez administrativo debe servir como su garante ${ }^{38}$. En ese sentido, respecto de las medidas cautelares cumple una doble función. Por un lado, constituye el fundamento mismo de su adopción, en tanto con ellas se busca garantizar el interés público de la justicia y no únicamente el interés individual de quien pretende el cumplimiento del pronunciamiento judicial. Al mismo tiempo deviene límite de las providencias cautelares, por cuanto en su otorgamiento debe asegurarse que el eventual daño que se pueda ocasionar a la comunidad sea menor que el que genere su no concesión. Por consiguiente, las decisiones que involucren este tipo de medidas deben estar presididas por la idea de que se cause la menor afectación posible al interés general. Esto significa que el deber de atender el interés general y la necesidad de asegurar la eficacia de la actuación administrativa imponen al juez un ejercicio de ponderación y de búsqueda de un equilibrio entre los intereses en conflicto al momento de tomar la decisión cautelar, de manera que esta no solo debe partir de la valoración del fumus boni iuris y el periculum in mora que concurre en la situación particular del solicitante, sino de la confrontación entre la exigencia de tutela y la de ejecución de la decisión administrativa combatida, porque así lo demanda el interés general al que debe servir eficazmente la Administración pública. Esto quiere decir que, aun en el supuesto de que fuera procedente la adopción de una medida cautelar por ser adecuada para garantizar el cumplimiento de la sentencia, esta pudiera excepcionalmente negarse por considerar el órgano jurisdiccional que el interés público demanda la ejecución de la decisión administrativa, hasta que se decida definitivamente el proceso.

Ahora bien, el interés general no es un concepto que pueda ser invocado en forma genérica para negar la tutela cautelar. Como bien señala Rodríguez-Arana, "no es un cheque en blanco, no es una fórmula abierta que permita el desencadenamiento de las

${ }^{36}$ García de Enterría, E. "La nueva doctrina del Tribunal Supremo sobre medidas cautelares: La recepción del principio del fumus boni iuris (Auto de 20 de diciembre de 1990) y su trascendencia general", Revista Española de Derecho Administrativo, No 69, 1991, p. 69.

${ }^{37}$ Coca, E. "A vueltas con la suspensión de la ejecución de actos administrativos recurridos: últimas aportaciones doctrinales y jurisprudenciales”, Revista de Administración Pública, No 127, 1992, p. 241.

${ }^{38}$ Conseil d'État (1999), http://www.conseil-etat.fr/ 
potestades administrativas sin más. Necesita ser demostrado en lo concreto, precisa ser puntualizado con detalle, debe ser específico y fácil de aprehender por la ciudadanía. De lo contrario, el concepto se convierte en un peligroso expediente para el autoritarismo y el ejercicio unilateral del poder" 39 .

\subsection{La contracautela}

La caución o contracautela, es una previsión de la ley contra los efectos de la medida cautelar eventualmente injusta, en tanto persigue la reparación de los daños provocados por su otorgamiento, si durante el proceso o en su resolución definitiva se revela que el derecho que en un principio aparecía como verosímil, al final no existía. Su función consiste en intentar asegurar la compensación de los perjuicios que pudiera causar la provisión cautelar o su suspensión a la parte contraria de quien se favorece con ella, y se determina bajo la responsabilidad de quien pretende la medida cautelar o quien en su caso solicita el levantamiento de la que fue acordada.

Quien resulta beneficiado con la resolución cautelar debe asumir la eventual obligación indemnizatoria de los daños y los perjuicios que resulten de su petición, obligación que queda supeditada a la circunstancia de que, en definitiva, no le asista el derecho que reclama y que sirvió de fundamento a la cautela. Con la exigencia de caución se pretende equilibrar la situación procesal de las partes, salvaguardando así el principio de igualdad.

La contracautela puede, en principio, constituirse sobre cualquiera de las formas de garantía del cumplimiento de las obligaciones, aunque es lo usual que en los procesos administrativos se exijan las de naturaleza real, principalmente la fianza. En cualquier caso, la naturaleza y el importe de la caución que habrá de imponerse deberá estar presidido por un juicio de proporcionalidad del juez, en el que deberá considerar la clase de la medida cautelar que se ha otorgado, los posibles perjuicios que puede causar, la apariencia de verosimilitud del derecho comprometido, así como las condiciones económicas del obligado a prestarla.

No cabe, por tanto, exigir una caución exorbitante que imposibilite su constitución y, por tanto, la funcionalidad de la cautela, o que comprometa la subsistencia del obligado a constituirla. No debe perderse de vista que el órgano jurisdiccional parte de evaluar una apariencia de buen derecho del actor frente a la apariencia de una actuación administrativa ilegal, desigualdad que deberá equilibrarse con la tutela cautelar.

La exigencia de caución, más que presupuesto para el otorgamiento de las medidas cautelares se configura generalmente como requisito para su operatividad, lo que significa que su ausencia no invalida la decisión cautelar, sino que determina su ineficacia; de manera que la ejecución de la medida o su continuidad quedará supeditada a que aquella sea prestada en el tiempo y la forma establecida por el juez.

${ }^{39}$ Rodríguez-Arana, J. Interés general, Derecho Administrativo y Estado de Bienestar, Centro de Estudios Estratégicos Syntagma-Iustel, Madrid, 2012, p. 15. 


\section{LA TUTELA CAUTELAR EN LA JURISDICCIÓN CONSTITUCIONAL}

Un hecho que resulta indiscutido y que salta a la vista de la simple lectura de la Constitución ecuatoriana es la dimensión que cobra la tutela cautelar como derecho fundamental, tanto por su reconocimiento expreso en determinados preceptos como por su indisoluble conexión con el también fundamental derecho a la tutela judicial efectiva.

En efecto, el art. 11, numeral 3 reconoce la justiciabilidad plena de todos los derechos, y el 75 garantiza el derecho de toda persona "al acceso gratuito a la justicia y a la tutela efectiva, imparcial y expedita de sus derechos e intereses, con sujeción a los principios de inmediación y celeridad" y sin quedar en ningún caso en indefensión. En la sección dedicada a las garantías jurisdiccionales de los derechos, el texto constitucional proclama (art. 87) la posibilidad de "ordenar medidas cautelares conjunta o independientemente de las acciones constitucionales de protección de derechos, con el objeto de evitar o hacer cesar la violación o amenaza de violación de un derecho", y, respecto de la materia ambiental, declara el compromiso del Estado de: "permitir a cualquier persona natural o jurídica, colectividad o grupo humano, ejercer las acciones legales y acudir a los órganos judiciales y administrativos, sin perjuicio de su interés directo, para obtener de ellos la tutela efectiva en materia ambiental, incluyendo la posibilidad de solicitar medidas cautelares que permitan cesar la amenaza o el daño ambiental materia de litigio" (art. 396).

La garantía de efectividad de los derechos impone, necesariamente, la exigencia de articulación de medidas precautorias que aseguren el resultado final del proceso, con lo que poco cabría dudar del anclaje constitucional de la tutela cautelar mediante su integración en el concepto de la tutela judicial efectiva.

Sin embargo, es un hecho que en el desarrollo por el legislador de estas garantías jurisdiccionales no se han extraído todas las consecuencias posibles de la normativa constitucional, en orden de garantizar una amplia y eficaz protección cautelar en los conflictos que involucran a la Administración pública, en todas sus esferas de actuación. Las prescripciones constitucionales han servido para conformar un régimen cautelar más o menos amplio en materia de acciones de protección de los derechos ante la jurisdicción constitucional; empero, contradictoriamente, no han sido suficientes para dar un tratamiento similar en la legislación procesal ordinaria.

En el sistema de la LOGJCC, si bien el régimen cautelar es bastante amplio y el otorgamiento de este tipo de medidas constituye la regla, su regulación parte de una fórmula bastante confusa, que, prima facie, deja muchas dudas respecto del alcance de la tutela cautelar. Según el art. 26: "Las medidas cautelares tendrán por objeto evitar o cesar la amenaza o violación de los derechos reconocidos en la Constitución y en instrumentos internacionales sobre derechos humanos (...) deberán ser adecuadas a la violación que se pretende evitar o detener, tales como la comunicación inmediata con la autoridad o persona que podría prevenir o detener la violación, la suspensión provisional del acto, la orden de vigilancia policial, la visita al lugar de los hechos. En ningún caso se podrán ordenar medidas privativas de la libertad". 
Esta previsión puede generar dos lecturas distintas: en primer lugar, puede entenderse como la adopción de una lista cerrada de las medidas cautelares que pueden disponer los jueces, habida cuenta de que la redacción del precepto no contiene ninguna fórmula que deje abierta la posibilidad de acordar otras innominadas. Esta interpretación, sin embargo, no se compadecería mucho con el propósito del declarado de la ley en su exposición de motivos de "que exista un procedimiento cautelar, expedito y eficaz que faculte a los órganos jurisdiccionales para dictar medidas urgentes en aquellos casos en que se amenace de modo inminente y grave un derecho, y de esta manera brinde protección oportuna y se eviten daños irreversibles", toda vez que las situaciones imaginables que pueden dar lugar a amenazas o vulneraciones de los derechos constitucionales sobrepasan la idoneidad de las específicas medidas cautelares dispuestas para enfrentarlas.

Otra interpretación pasa por entender la expresión "tales como", no como una enumeración taxativa y cerrada de las provisiones precautorias, sino como una lista de aquellas más comunes e idóneas a los propósitos de la institución, a modo de ejemplos pero no limitada a estas; y al mismo tiempo entender el "en ningún caso se podrán ordenar medidas privativas de la libertad”, como el único límite material al poder cautelar del juez; es decir, considerándolo facultado para adoptar, además de las ya previstas expresamente en el propio precepto, cualquier otra medida que considere adecuada para detener la amenaza o vulneración del derecho, excepto aquellas que impliquen privación de libertad. Esta interpretación deriva de un análisis sistemático de la propia ley, que en el art. 33 estatuye que el juez "especificará e individualizará las obligaciones, positivas y negativas, a cargo del destinatario de la medida cautelar y las circunstancias de tiempo, modo y lugar en que deben cumplirse", lo que puede entenderse como una habilitación para ordenar cualquier obligación idónea a los fines de la tutela de los derechos. Tal interpretación se complementa con el contenido de reparación integral de las sentencias en este tipo de procesos (arts. 88 ConsE y 18 y 19 de la propia LGJCC), ya que si la resolución definitiva ha de tener tan amplio contenido, habrá que asumir que las medidas preventivas deberán tener un alcance similar que lo garantice.

En cualquier caso no debe de dejar de señalarse la deficiente técnica regulatoria del legislador, que bien podía haber optado por la enumeración de unas medidas nominadas, como hizo, y luego incluir una fórmula general que apoderase al juez para decidir cualesquiera otras no incluidas en la lista que fueran adecuadas a los efectos de la protección de los derechos, con lo que se hubiese evitado cualquier polémica o confusión.

En cuanto a los presupuestos para su otorgamiento de las medidas cautelares, en la LGJCC se atiende particularmente al periculum in mora, al determinar que aquellas procederán ante una amenaza o vulneración de un derecho de modo inminente y grave por su capacidad para ocasionar daños irreversibles o por la intensidad o frecuencia de la violación (art. 27) y que deberán ser ordenadas de manera inmediata y urgente (art. 30), aun de forma verbal y sin necesidad de audiencia de parte ni de notificación formal (art. 33). Respecto del fumus boni iuris, este cobra aún mayor relevancia que el presupuesto tradicional, no solo al establecerse que el juez lo valorará al momento mismo de presentarse los hechos en que se funda la reclamación y sin exigir prueba 
alguna (art. 33), sino porque además la ley contiene una presunción iuris tantum de buen derecho solamente con la presentación de la demanda, invirtiendo la carga de la prueba hacia la institución pública o hacia el particular cuando se aleguen hechos de discriminación o violaciones a los derechos del ambiente o la naturaleza (art. 16 in fine $)^{40}$, lo que supone una derogación en estos supuestos del principio de presunción de validez de los actos administrativos.

Por otra parte, la LGJCC no contiene ninguna referencia a la valoración del interés general como presupuesto o límite para la adopción de medidas cautelares a pesar de que las acciones de protección podrían interponerse contra "toda política pública, nacional o local, que conlleve la privación del goce o ejercicio de los derechos y garantías” (art. 41.2 LGJCC y 88 ConsE); situación que merece un análisis crítico.

La administración pública, por definición constitucional (art. 227 ConsE), constituye un servicio a la colectividad que se rige, entre otros, por los principios de eficacia y eficiencia, lo que en principio justifica la efectividad y ejecutoriedad de los actos administrativos. Por tal razón, no es admisible que en un procedimiento informal, sencillo, rápido e inmediato como es el cautelar, en el que además como regla general se presume la apariencia de buen derecho, no quepa tener en cuenta la posible perturbación que a los intereses generales puedan generar las medidas acordadas, sobre todo si esta pudiera ser tan o más grave que la que el acto causa al accionante.

Ciertamente la interpretación que hace el legislador acerca del fundamento de la tutela cautelar está orientada básicamente a ponerla en función de asegurar la vigencia de los derechos constitucionales y, en consecuencia, al momento de fijar los criterios para su concesión, prescinde de tener en cuenta otros parámetros desconectados con esa finalidad, como lo es la ponderación de intereses. Pero contrariamente, hay que argumentar que la necesidad de que la Administración pública sirva con eficacia a los intereses de la colectividad también cuenta con un inequívoco soporte constitucional, y que los derechos reconocidos en el magno texto no son absolutos, sino que tienen unos límites que emanan precisamente de la coexistencia de otros derechos o principios que también han merecido la protección del constituyente.

El juicio cautelar, precisamente por su carácter provisional, es un juicio necesariamente ponderativo, que está llamado a alcanzar un difícil equilibrio entre los intereses en conflicto, en el que necesariamente tendrá que calibrarse si otros intereses distintos de los del recurrente que solicita la tutela cautelar, pero igualmente dignos de protección, pueden sufrir como consecuencia de la adopción de la medida, un daño

${ }^{40} \mathrm{El}$ precepto en su parte inicial expresa que "la persona accionante deberá demostrar los hechos que alega en la demanda o en la audiencia, excepto en los casos en que se invierte la carga de la prueba”, y en su parte final, además de definir los supuestos específicos en que se produce dicha inversión (discriminación, derechos ambientales o no aportación de la información solicitada a la entidad pública), determina que "se presumirán ciertos los hechos de la demanda cuando la entidad pública accionada no demuestre lo contrario...", lo que hace entender que, en los conflictos con entidades públicas, siempre habrá de corresponder a esta la carga de la prueba. 
de las mismas característica del que con la medida se trata de evitar, es decir, de difícil o imposible reparación ${ }^{41}$.

En relación con este asunto, el art. 85 ConsE estipula que: "Sin perjuicio de la prevalencia del interés general sobre el interés particular, cuando los efectos de la ejecución de las políticas públicas o prestación de bienes o servicios públicos vulneren o amenacen con vulnerar derechos constitucionales, la política o prestación deberá reformularse o se adoptarán medidas alternativas que concilien los derechos en conflicto”.

Este mandato constitucional no debe entenderse dirigido únicamente a los que formulan o ejecutan las políticas públicas, sino a todos aquellos con la capacidad de poder "adoptar las medidas alternativas" que concilien los intereses en conflicto, como es el caso de los tribunales. Ello no quiere decir que siempre que se produzca una colisión tendrá que hacerse prevalecer al interés general sobre la medida cautelar, pero lo que no puede aceptarse es que, sencillamente, se prescinda de tenerlo en cuenta.

En ese sentido, en dependencia de las circunstancias del caso, la posible perturbación de graves consecuencias al interés general debería servir de justificación a la denegación de una medida cautelar sobre todo si la apariencia de razón no aparece lo suficientemente acreditada o el perjuicio que se pretende evitar con su adopción es de menor entidad que el que produciría su otorgamiento. $\mathrm{O}$, en sentido contrario, como no puede aceptarse la persecución de un interés general insignificante a costa del extraordinario sacrificio de un interés privado, cuando el perjuicio que sufriría el interés particular de no adoptarse la medida cautelar fuese notablemente superior al que resultaría para el interés público, en caso de que sí se otorgara dicha medida se invierte la solución del conflicto planteado: se sacrifica el interés público en favor del interés privado que viene satisfecho con la concesión de la medida cautelar ${ }^{42}$.

Por último, en lo que se refiere a la contracautela, la propia naturaleza de la tutela cautelar regulada por la LGJCC, garantista de la posición jurídica del reclamante, determina que el legislador haya omitido la posibilidad de que se pueda exigir caución para responder por los eventuales perjuicios que puedan derivarse de la concesión de la medida a la persona contra la que se dirija o que pueda resultar indirectamente afectada por la misma. La exigencia de contracautela haría perder esa finalidad protectora urgente para quien demanda el cese de la amenaza o vulneración del derecho, pero, al mismo tiempo, provoca una situación de desigualdad procesal en tanto el perjudicado con la disposición cautelar no cuenta con las garantías necesarias para que pueda resarcirse el daño si, a final de cuentas, la medida resultare injusta. De momento, la única precaución contenida en la ley contra las solicitudes maliciosas o temerarias de providencias cautelares radica en la facultad correctiva de los jueces y en la exigencia de responsabilidad civil y penal a quienes incurran en estas conductas (art. 23).

\footnotetext{
${ }^{41}$ Chinchilla, C. "Tutela cautelar”..., ob. cit., p. 591.

${ }^{42}$ Hernández Corchete, J. “Medidas cautelares en lo contencioso administrativo...”, ob. cit., p. 81.
} 


\section{EL RÉGIMEN CAUTELAR EN LOS PROCESOS CONTENCIOSO-ADMINISTRATIVO Y CONTENCIOSO-TRIBUTARIO DEL Código ORgÁNiCO General de Procesos}

La tutela cautelar ante la justicia administrativa se recoge en dos escenarios del COGEP. En el régimen procesal común, bajo el rubro de "providencias preventivas" (título III del Libro II), se regulan las medidas tradicionales de los procesos civiles o mercantiles como el secuestro o retención del objeto del litigio, el arraigo o la prohibición de enajenar bienes inmuebles, las que al estar ubicadas en la parte general resultan aplicables a todos los procesos y que son atinentes a las controversias en que se litiguen bienes o derechos de crédito. En los artículos 324 y 330, la única específica para los procesos contenciosos administrativo y tributario: la suspensión de la ejecución del acto impugnado.

Respecto del contenido en la LGJCC, el régimen de tutela cautelar del COGEP frente a la actividad administrativa se sitúa en las antípodas, a pesar de ser más reciente. Si en aquella la concesión de medidas cautelares constituye la regla, en este, es la excepción.

Siendo la tutela cautelar una función instrumental respecto de la tutela judicial ordinaria, es evidente que, como esta, participa de los principios vertebradores del control jurisdiccional de la Administración pública. En este sentido, si bien en la formulación del objeto del proceso (art. 300) puede verse una apertura hacia el control universal de la actividad administrativa, cuando se habla del control de legalidad de los hechos administrativos y la resolución de los diversos aspectos de la relación jurídico tributaria o jurídico administrativa, incluso la desviación de poder, es este el único precepto en el que se habla en esos términos, pues el resto del articulado se refiere únicamente al acto administrativo, con lo cual se mantienen los tintes clásicos de la función revisora propia del modelo francés tradicional que sirvió de inspiración al orden procesal ecuatoriano y cuya característica distintiva es la articulación de un proceso que gravita alrededor del acto administrativo, lo que determina que la cuestión de la tutela cautelar se vincule, precisamente, a la figura del acto administrativo; lo que unido a la presunción de legitimidad y fuerza ejecutoria que este goza (arts. 311 y 329), suscita que la solución arbitrada quede reducida a la técnica de la suspensión de la ejecución con carácter excepcional, negando por tanto efectos suspensivos sobre dicha ejecución a la interposición de la demanda.

Así, según el art. 330: “A petición de parte, el juzgador podrá ordenar en el auto inicial la suspensión del acto administrativo, cuando de los hechos alegados en la demanda y las pruebas acompañadas, aparezca como justificado un juicio provisional e indiciario favorable a la pretensión exhibida, sin que esto implique una decisión anticipada sobre el fondo, siempre que el retardo en la decisión de la causa pueda afectar irremediablemente el derecho opuesto y se evidencie la razonabilidad de la medida...".

La explicación teórica de esta forma de entender el régimen cautelar se sustenta en una interpretación no muy bien justificada de los principios de la autotutela administrativa, que han llevado a una práctica identificación entre la autotutela ejecutiva y la 
declarativa. En efecto, la noción de poder ingénita al concepto mismo de Administración pública, ha conllevado a una identificación entre la idea de acto administrativo unilateral y presuntamente válido, con su eficacia inmediata y forzosa ejecutoriedad. El acto administrativo se presenta como un acto de imperium que, al concretar la voluntad de la ley y representar un interés general, se ha de presumir legítimo y requerirá de su ejecutividad irresistible e inmediata que no puede detenerse por el hecho de que se cuestione esa legitimidad.

Esta explicación, sin embargo, no resulta del todo satisfactoria. Si bien es cierto que de la Administración se requiere un funcionamiento eficaz y, en virtud de ello ha de estar dotada de amplios poderes de autotuela, tanto para producir la decisión como para llevarla a cabo por sus propios medios, ello no quiere decir que tenga que existir una necesaria e inseparable conexión entre la legitimidad y eficacia de la decisión con su ejecutoriedad inmediata. Concretamente, la eficacia de la actividad administrativa en la satisfacción del interés general no en todos los casos depende de la ejecución inmediata del acto administrativo, pues esta en ocasiones se puede deferir en el tiempo ${ }^{43}$.

Vistas así las cosas, si el fundamento de la ejecutividad del acto es la necesidad de la eficacia administrativa en la satisfacción del interés general, entonces no tendría sentido predicar la operatividad de aquella cualidad en tanto ese interés no requiera de una ejecución inmediata del mismo ${ }^{44}$; y en ese sentido, la tutela cautelar solo tendría razón de intervenir cuando, reclamando el interés general la eficacia inmediata del acto, prevalezca por encima de ese interés el de garantizar la eficacia de la resolución judicial. En esa lógica se asienta el ordenamiento procesal alemán ${ }^{45}$, que construye su régimen cautelar desde la perspectiva de la tutela judicial efectiva y otorga, como regla general, poder suspensivo de la ejecución del acto a la interposición de la demanda, salvo los supuestos en que, según las características de cierta clase de actos administrativos, solo pueda paralizarse su efectividad por el juez previa consideración de las circunstancias concurrentes en cada caso.

Respecto de los presupuestos para disponer la medida de suspensión en el contencioso administrativo, el art. 330 la hace depender del cumplimiento de tres condiciones: La primera se refiere a la existencia del fumus boni iuris, en tanto se exige "que aparezca como justificado un juicio provisional e indiciario favorable a la pretensión exhibida". La segunda, "que el retardo en la decisión de la causa pueda afectar irremediablemente el derecho opuesto", o sea, de la valoración del periculum in mora. Significa que habrá que demostrar de forma categórica que el perjuicio que se ocasiona con la ejecución de la disposición es de tal magnitud que haría imposible su reparación si llega a prosperar

43 Cabría aquí pensar, por ejemplo, en los actos que imponen sanciones pecuniarias o limitan la participación de los administrados en procesos de selección. En estos casos la actividad administrativa no se detendría ni se afectaría el interés general porque no se cobre la deuda inmediatamente o porque se le dé participación a un candidato en un proceso de selección aunque luego se compruebe que no tenía derecho a ello.

${ }^{44}$ Este es el criterio seguido respecto de los actos de determinación de la deuda tributaria (art. 324), a los que condiciona la suspensión de la ejecución únicamente a la prestación de caución.

${ }^{45}$ Ver al respecto supra las notas 15 y 16. 
la demanda. Por tanto, no es suficiente la invocación formal de la afectación al derecho, sino que se requiere una alegación razonada acerca de la previsibilidad de los daños y una adecuada determinación cualitativa y cuantitativa que permita una evaluación apropiada respecto de la procedencia o no de quebrar la ejecutividad del acto administrativo.

La tercera condición exige la razonabilidad de la medida cautelar. La determinación de la razonabilidad pasa por un juicio de ponderación de todos los intereses en juego, tanto del demandante como los de un tercero afectado, o el interés general; de manera que deberá evitarse que, con la medida cautelar, los intereses generales a los que responde el acto administrativo puedan sufrir también una lesión difícil o imposible de reparar. No ha tratarse de cualquier clase de lesión, sino de aquella de carácter grave, o por lo menos de una intensidad superior a la que pueda resultar del proceso favorable al reclamante. Si al evaluarse la suspensión del acto existen fundadas razones para suponer que con la estimación de la pretensión los costos para la Administración en reparar el daño son superiores a los beneficios que se obtienen con su ejecución, deberá accederse a la suspensión.

La ley no hace depender la medida de suspensión de la ejecución del acto de la prestación de caución, lo que supone mayores garantías de acceso a la justicia para el afectado con la decisión presuntamente ilegal, aunque ello supone al mismo tiempo la renuncia a las garantías de reparación de las consecuencias económicas que se deriven de su acción si al final no se le concede la razón.

En lo que respecta al contencioso-tributario, la suspensión de la ejecución del acto administrativo es relativamente más flexible, en tanto no se exige la concurrencia de los clásicos presupuestos del fumus boni iuris y el periculum in mora. Conforme prevé el art. 324, cuando el acto administrativo en materia tributaria impugnado imponga al administrado una obligación de dar, basta con solicitar la suspensión en la demanda para que esta proceda, debiendo rendir caución del diez por ciento (10\%) de la obligación para que se haga efectiva; lo que, más que caución, resulta una modalidad atenuada de la muy cuestionada y hoy en vía de extinción regla del solve et repete.

Nótese la enorme contradicción que envuelve la regulación de la medida cautelar en estos dos tipos de proceso. Por un lado no se exige caución para suspender la ejecución del acto cuando podría hacerse, esto es, para asegurar el posible resarcimiento de los daños que pueda generar la provisión cautelar si al final se resuelve la improcedencia de la pretensión y, por otro, se requiere cuando no sirve para que cumpla su finalidad propia y su única función es generarle una carga al administrado.

$\mathrm{Y}$ es que, tanto las deudas o sanciones tributarias como las reclamaciones económicoadministrativas en general, son los supuestos típicos en los que los ordenamientos han negado el privilegio de la ejecutoriedad inmediata cuando son impugnados, por cuanto el interés general no sufre ninguna perturbación significativa si se espera a que se resuelva en conflicto planteado. Por tanto, no se entiende qué función puede cumplir la caución que reclama el art. 324 del COGEP que no sea imponer una carga innecesaria al reclamante si, en definitiva, la afectación que puede causar a la hacienda pública el impago temporal de la deuda tributaria no ha de ser de tal magnitud que no pueda esperar la verificación por el juez de su legitimidad (a menos de que se trate del improbable 
supuesto de que todos los contribuyentes impugnen sus deudas al mismo tiempo y el Estado se quede sin recursos) y, en el caso de no llegar a prosperar la demanda, la Administración puede cobrar la deuda en su totalidad de la misma manera que cobraría el $90 \%$ restante.

\section{CONCLUSIONES. BASES PARA LA REFORMA DEL RÉGIMEN CAUTELAR}

La manera en que hoy se concibe al régimen cautelar en los procesos contenciosoadministrativo y tributario, sobre la base la suspensión de la ejecución como única medida de reconocimiento explícito y con una inadecuada técnica en su la regulación, es una deficiencia evidente del contencioso administrativo ecuatoriano, que exige una armonización que resulte apropiada a las exigencias de justicia, y que devengan en definitiva en verdaderas garantías de la eficacia de la actividad jurisdiccional y no un obstáculo para la obtención de la satisfacción de un derecho o un interés que haya sido atacado o desconocido. La tutela cautelar no debe continuar restringida a la figura de la suspensión de la ejecución de las resoluciones administrativas, ni tampoco configurarse esta como una excepción, sino como potestad atribuida al tribunal que pueda ejercer siempre que la estime pertinente, mediante una ponderación adecuada y razonada de los intereses en juego. Cuando la suspensión no es idónea para proteger cautelarmente la situación jurídica del reclamante, negar absolutamente la posibilidad puede adoptar otro tipo de medida, incluso de contenido positivo, elimina toda posibilidad de asegurar la eficacia de la eventual sentencia favorable al demandante y con ello anula la virtualidad del derecho a la tutela judicial efectiva.

Por otra parte, el conflicto entre las prerrogativas públicas y las posiciones subjetivas particulares no debe entenderse en el plano teórico, desde la confusión e identificación de la autotutela declarativa (capacidad de emitir decisiones unilaterales) con la ejecución forzosa de lo decidido, ni tampoco resolverse, por tanto, de forma simplificada sobre la base de la regla general de la preeminencia formal de la autoridad sobre las posiciones particulares. En definitiva, la eficiencia y continuidad de la función administrativa que requiere la satisfacción del interés general no pueden seguir enarbolándose como dogmas inflexibles que detraigan el derecho del ciudadano a una justicia pronta y efectiva.

La construcción de un adecuado régimen de tutela cautelar debería partir de las siguientes líneas básicas:

a) La formulación de una amplia disponibilidad de medidas cautelares en manos del órgano judicial, mediante un numerus apertus, de manera que el juzgador pueda acordar cuantas sean necesarias para asegurar la eficacia de la sentencia, entre ellas la adopción de medidas positivas para asegurar los bienes objeto de la litis o ciertas comprobaciones de hechos necesarios para la posterior tramitación del proceso. Que a estas alturas de la evolución del derecho administrativo, la tutela judicial y, consecuentemente, la cautelar, deban abarcar toda la amplia variedad de formas 
de actuación administrativa es algo que no requiere de mayor demostración. La plenitud del sometimiento de la justiciabilidad de la Administración y el riesgo que durante la pendencia del proceso pueden correr las situaciones jurídicas de los administrados, producto de la propia dinamicidad de la actuación de la Administración y las prerrogativas que puede actuar, reclaman de la extensión de las posibilidades de control judicial de esta y una mayor tutela de aquellas.

b) En cuanto a la técnica de suspensión de la ejecución, se impone una articulación consecuente con la variedad de pronunciamientos y efectos que pueden derivar de un acto administrativo. De esta manera, el régimen cautelar debe partir de la distinción entre la presunción de legitimidad y fuerza ejecutiva de los actos unilaterales (que será distinta en función de la regulación y de las situaciones que afecten) y de la eficacia inmediata de dichos actos (que se requerirá en la medida en que su naturaleza lo amerite); lo que permitiría superar la regla general de ejecutoriedad indiscriminada de los actos administrativos, pudiendo incluso invertirse esta o al menos establecer una relación a priori de actos que no necesitan beneficiarse de la cualidad ejecutoria, produciendo la acción impugnatoria contra ellos efectos suspensivos.

c) En los casos en que, de conformidad con los fundamentos expuestos en el inciso anterior, se conceda carácter suspensivo de la ejecución a la demanda por no suponer afectación importante al interés general, deberá prescindirse de la exigencia de caución, por no cumplir su finalidad propia.

\section{BIBLIOGRAFÍA}

Allena, Miriam. y Fracchia, Fabrizio, "Il ruolo e il significato della tutela cautelare”, Diritto Processuale Amministrativo, $\mathrm{N}^{\circ} 1,2011$.

Aguirre Guzmán, Vanessa, El derecho a la tutela judicial efectiva: una aproximación a su aplicación por los tribunales ecuatorianos”, Foro, Revista de Derecho, UASB, N 14, 2010.

Calamandrei, Piero, Introducción al estudio sistemático de las providencias cautelares, trad. de S. Santis, Buenos Aires, Editorial Bibliográfica Argentina, 1945.

Carrillo, Santiago, "Medidas cautelares contra el Estado en Argentina", en Damsky, Isaac et al. (coords.): Las Medidas Cautelares en el Proceso Administrativo en Iberoamérica, México, Asociación de Magistrados de Tribunales de lo Contencioso Administrativo de los Estados Unidos Mexicanos, 2009.

Cassagne, Juan C. y González Pérez, Jesús, La Justicia Administrativa en Iberoamérica, Buenos Aires, LexisNexis-Abeledo Perrot, 2005.

Chinchilla, Carmen, "El derecho a la tutela cautelar como garantía de la efectividad de las resoluciones judiciales”, Revista de Administración Pública, No 131, 1993.

, "Tutela cautelar", en Leguina, Jesús y Sánchez Morón, Miguel (dirs.) Comentarios a la Ley de la Jurisdicción contencioso-Administrativa, Valladolid, LexNova, 1999.

, La tutela cautelar en la nueva justicia administrativa, Madrid, Civitas, 1991.

Chiovenda, Giusseppe, (1936): Instituciones de Derecho Procesal Civil (trad. de la segunda edición italiana y notas de derecho español de E. Gómez Orbaneja, Madrid, Revista de Derecho Privado), 1936. 
CocA, Eduardo, "A vueltas con la suspensión de la ejecución de actos administrativos recurridos: últimas aportaciones doctrinales y jurisprudenciales”, Revista de Administración Pública, $\mathrm{N}^{\circ} 127,1992$.

Cortés Domínguez, Valentín et al., Derecho Procesal Civil. Parte General Madrid, Colex, 2001.

DAMSKY, Isaac et al. (coords.), Las Medidas Cautelares en el Proceso Administrativo en Iberoamérica, México, Asociación de Magistrados de Tribunales de lo Contencioso Administrativo de los Estados Unidos Mexicanos, 2009.

De la Serna, María, "Las medidas cautelares", Documentación Administrativa, No 254-255, 1999.

Fenor de la Maza, Ángel, Nuevas Perspectivas en el Proceso Contencioso-Administrativo, Madrid, Montecorvo, 1997.

FonseCA, Isabel, "Os Processos cautelares na justica administrativa. Uma parte da categoria da tutela jurisdicional de urgencia", en Pereira da Silva, Vasco (coord.), Temas e problemas de processo administrativo, Lisboa, Instituto de Ciências Jurídico-Políticas segunda edición revisada y actualizada, 2011, p. 208.

Fuertes, Mercedes, "Tutela cautelar e impugnación de reglamentos", Revista de Administración Pública, $\mathrm{N}^{\circ} 157,2002$.

Gallegos Fedriani, Pablo, Las medidas cautelares contra la Administración pública, Buenos Aires, Ábaco, segunda edición, 2002.

García de Enterría, Eduardo, "La nueva doctrina del Tribunal Supremo sobre medidas cautelares: La recepción del principio del fumus boni iuris (Auto de 20 de diciembre de 1990) y su trascendencia general”, Revista Española de Derecho Administrativo, No 69, 1991, p. 69.

, “La aplicación de la 'apariencia de buen derecho' como base de las medidas cautelares en el recurso directo contra reglamentos", Revista de Administración Pública, No 125, 1991.

, La batalla por las medidas cautelares, Madrid, Civitas 1995.

GonzÁlez Pérez, Jesús, "La Justicia Administrativa”, en Cisneros Farías, Germán et al. (coords.), Justicia Administrativa, Segundo Congreso Iberoamericano de Derecho Administrativo, México, UNAM, 2007.

Gordillo, Agustín, Tratado de Derecho Administrativo y obras selectas, Buenos Aires, Fundación de Derecho Administrativo, 2013.

HERNÁNDEZ Corchete, Juan A., "Medidas cautelares en lo contencioso administrativo y Constitución. Una propuesta para un debate aún abierto", Cuadernos de Derecho Público, No 10, 2000.

López Ramón, Fernando, "Límites constitucionales de autotutela administrativa", Revista de Administración Pública, $\mathrm{N}^{\circ} 115,1988$.

Navarro, Karlos y Sendín, Miguel. A., "Medidas cautelares y proceso contencioso-administrativo en Nicaragua", en Damsky, Isaac et al. (coords.): Las Medidas Cautelares en el Proceso Administrativo en Iberoamérica, México, Asociación de Magistrados de Tribunales de lo Contencioso Administrativo de los Estados Unidos Mexicanos, 2009.

Ottolenghi, M., "Medidas precautorias", Estudios de Derecho Procesal en Honor de Hugo Alsina, Buenos Aires, Ediar S. A. Editores, 1946.

Parejo, Luciano, "La tutela judicial cautelar en el orden contencioso administrativo", Revista Española de Derecho Administrativo, No 49, 1986.

Parejo, Luciano, Derecho Administrativo, Barcelona, Ariel, 2003.

Podettr, José R., Tratado de las Medidas Cautelares, Buenos Aires, Ediar S.A., segunda edición actualizada por el Dr. Victor A. Guerrero Leconte, 1969.

Rodríguez-Arana, Jaime, Interés general, Derecho Administrativo y Estado de Bienestar, Madrid, Centro de Estudios Estratégicos Syntagma-Iustel, 2012.

Schmidt-Assmann, Eberhard, La Teoría General del Derecho Administrativo como Sistema, MadridBarcelona, Instituto Nacional de Administración Pública- Marcial Pons, 2003. 
